\title{
Professor Andreas Weiglein, MD
}

\author{
Jose Sanudo (iD \\ Department of Anatomy and Human Embryology, Faculty of Medicine, Universidad Complutense de Madrid, Madrid, Spain \& President, EACA \\ Anatomy 2020;14(1):10 @2020 Turkish Society of Anatomy and Clinical Anatomy (TSACA)
}

Prof. Dr. Andreas Weiglein was a great scientist and a very good friend. He was a perfect teacher not only in classical gross anatomy but also a perfect promoter in developing alternative methodologies for preservation of bodies such as Thiel's embalmment and plastination. $\mathrm{He}$ served as the President of European Association of Clinical Anatomy for many years and also as the President of the International Society of Plastination for a long time. He was always involved in building bridges between cultures and increasing communication among colleagues from different countries. In 2002 he organized an unforgettable joint meeting of the European and American Associations of Clinical Anatomy in Graz. That meeting was an excellent platform for planning a lot of future projects among anatomists all over the world. The last meeting, he attended was the International Meeting of Clinical Anatomy held in 2018 in Madrid. Although he was very ill, he previously promised me to attend the meeting and he was there. I attached the photo with his students below who learned a lot from him until the last minute.

Good bye my friend!

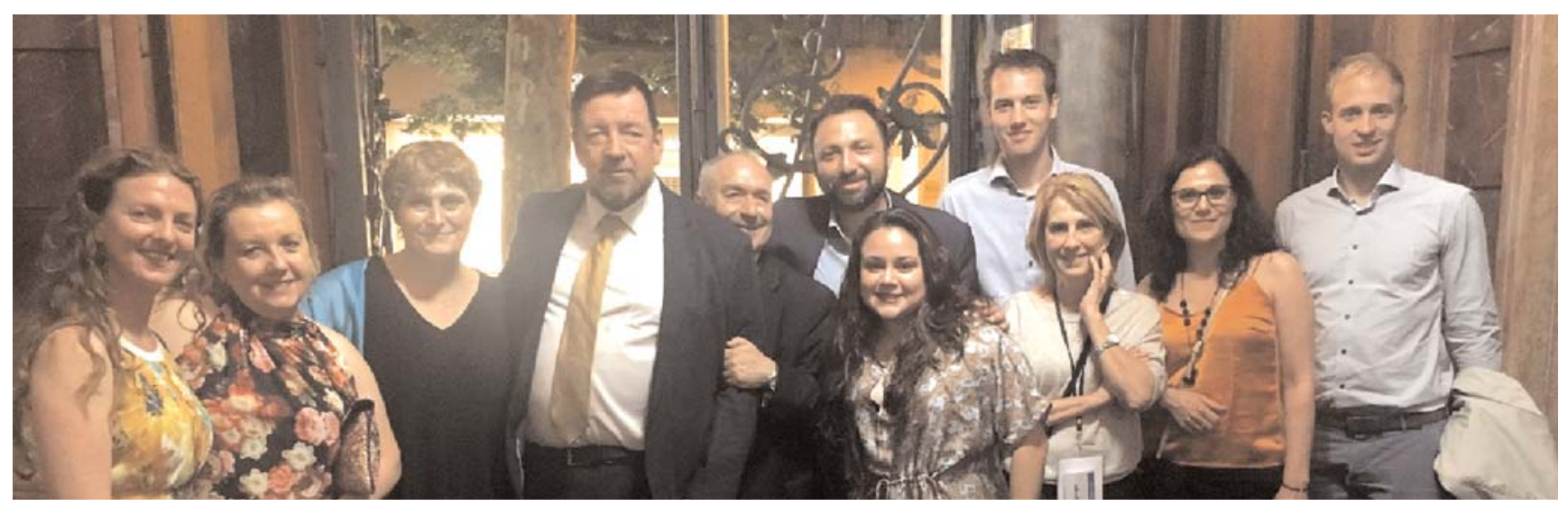

Figure 1. Andreas Weiglein with his students, 2018, Madrid.

ORCID ID:

J. Sanudo 0000-0002-6396-2691
Correspondence to: Jose Ramon Sanudo Tejero, MD, PhD Department of Anatomy and Human Embryology, Faculty of Medicine, Universidad Complutense de Madrid, Madrid, Spain Phone: +34913941381 e-mail: jrsanudo@ucm.es

Conflict of interest statement: No conflicts declared.

This is an open access article distributed under the terms of the Creative Commons Attribution-NonCommercial-NoDerivs 3.0 Unported (CC BY-NC-ND3.0) Licence (http://creativecommons.org/licenses/by-nc-nd/3.0/) which permits unrestricted noncommercial use, distribution, and reproduction in any medium, provided the original work is properly cited. Please cite this article as: Sanudo J. Professor Andreas Weiglein, MD. Anatomy 2020;14(1):10. 